\title{
Strength characteristics of fiber-reinforced light shotcrete
}

\author{
Konstantin Alekseev* and Alexsander Kurilko
}

Chersky Institute of Mining of the North, Siberian Branch, Russian Academy of Sciences (IGDS SO

RAN), 677980, Yakutsk, Russian Federation

\begin{abstract}
The article presents the regularities of the flexural and compressive strength variation, as well as the energy intensity of destruction of light heat-shielding vermiculite concrete, depending on the content of polypropylene or basalt fiber. The paper stresses that the greatest increase in flexural strength of $40 \%$ is observed at the polypropylene or basalt fiber that the greatest increase in flexural strength of $40 \%$ is observed at the polypropylene or basalt fiber of 2 and $2-4 \%$ respectively. As the basalt fiber content increases from 1 to $4 \%$, the compressive strength increases from 42 to $83 \%$. The resistance of vermiculite concrete to dynamic bending loads when the polypropylene fiber ranges from 0.5 to $2 \%$ by a factor of 2.54 .2 . With basalt fiber content of 1 to $4 \%$ the energy intensity of destruction increases 1.52 .5 times.Specific energy intensity of destruction of samples reinforced with basalt fiber increases by $2.3 \div 2.7$ times during volumetric destruction of the specimens under study on a vertical pile driver. The regularities obtained in the course of the studies indicate that fiber reinforcement of light heat-shielding vermiculite concrete increase its strength characteristics and thereby expand the scope of its application.

Keywords: heat-shieldingshotcrete, permafrost zone, polypropylene fiber, basalt fiber, composite material, flexural and compressive strength, energy intensity of destruction
\end{abstract}

\section{Introduction}

Underground method of mining becomes more and more widespread in accordance with development of diamond, gold, coal and industries of Republic Sakha (Yakutia). In this context, the question of choosing rational, reliable and economical means of supporting of working mines in permafrost zone becomes relevant

Almost all authors report the dependence of the stability of mine workings on temperature. Depending on the thermal status of the mine and the type of face support used, permafrost rocks may thaw, be exposed to freezing-thawing cycles, suffocation, precipitation, frost, ice sublimation.

For example, alternating temperatures on carbonate rocks and kimberlite ores from Yakutia diamond deposits reduce their strength to complete self-destruction [1]. Some

* Corresponding authors: const1711@mail.ru 
reduction in the resistance of permafrost mines due to seasonal or progressive thawing of the surrounding rocks, observed in any thermal operating mode [2].

Comprehensive studies on the construction of heat-protective torque-concrete coatings in the conditions of negative temperatures of the rock mass and atmosphere of the mines in permafrost have been carried out at the Institute of Chersky Mining of the North SB RAS $[3,4]$. Formulations of thermal shotcretewith the use of fillers of local production, vermiculite, ceramic, azerite, are developed. They have been found not only to protect the permafrost rocks from the impact of the aggressive mining atmosphere, but also to reduce several times the number of freezing-thawing cycles of the test sediments during the year and also reduce the size of the halos of thawing around the opening mineworkings in summer [5]. However, due to low strength and low frost resistance, heat-shielding torque concrete coatings are not widely used

In addition, there are deficiencies in all cement binder construction materials, such as weak impact resistance and low tensile strength. In addition, they have inherent disadvantages typical of all building materials on a cement binder, in particular, weak resistance to shock loads and low tensile strength.

One way to increase the strength of building materials on cement binders is to introduce fibrous materials (fiber) [6-8] into the mixture and to produce a dispersed composite building material on this basis. The range of fibers used is very extensive: from extremely scarce, for example, carbon, boron, tungsten, to those comparatively available for use in mass construction - steel, basalt, polypropylene, etc.The fiber to be used must meet a number of requirements: high strength, chemical resistance, evenly distributed in the volume of the cement test or concrete without the formation of heterogeneous bundles adversely affecting the final strength of the product. The cost of reinforcing materials and the volume of their production are also important. In this regard, polypropylene and basalt fiber are noteworthy. In connection with the above, the regularities of changes in the physical and mechanical characteristics of light vermiculite concrete, depending on the fiber content, investigate (fig. 1).

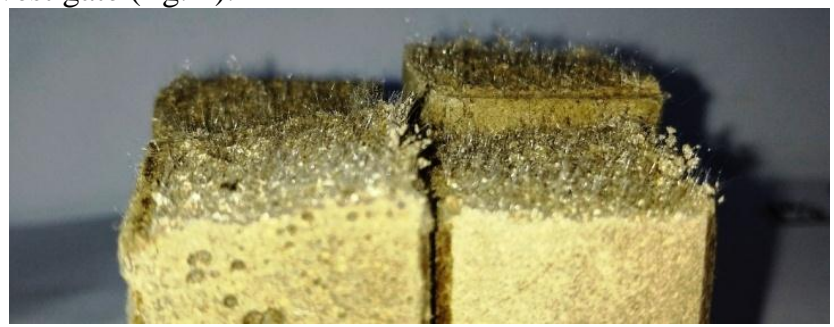

Fig. 1. Bend a sample of concrete reinforced with polypropylene fiber

The tensile strength of the vermiculite concrete during flexibility and compression determines according to GOST 10180-90, GOST 310.4-81, GOST 53231-2008.

The following materials are used to make the samples:

- cement M400 (production of JSC «Yakutcement», Yakutsk), bulk density $1194 \mathrm{~kg} / \mathrm{m}^{3}$, true density $3121 \mathrm{~kg} / \mathrm{m}^{3}$;

- polypropylene fiber (mark VSM-6) which is coated with a lubricating agent to facilitate the dispersion and adhesion of fiber with cement, diameter $10 \div 15 \mathrm{mkm}$, length 6 $\mathrm{mm}$;

- basalt fiber VC23-6-61 lubricant water emulsion №61, length 6мм, diameter 23mkm;

- concreteM400 (production of JSC «Yakutcement»), bulk density $1194 \kappa \Gamma / \mathrm{M}^{3}$, true density $3121 \kappa \Gamma / \mathrm{M}^{3}$;

- vermiculite sand fraction $0,6 \div 2 \mathrm{~mm}$ VVT-150 GOST 12865-67 (production of "PO Himcentr", Ltd., Novosibirsk), bulk density $\approx 305 \mathrm{~kg} / \mathrm{m}^{3}$. 
The fiber content of the mixture varies from 0.5 to $4 \%$ of the total mass of the components of the mixture (table 1).

Table 1. Consumption of "Cement/Vermiculite" mixture components=1/2 (volume)

\begin{tabular}{|c|c|c|c|c|c|c|}
\hline \multirow{2}{*}{ Type of fiber } & \multirow{2}{*}{$\begin{array}{c}\text { Fiberconte } \\
\text { nt, } \%\end{array}$} & \multirow{2}{*}{$\begin{array}{c}\text { Water/ } \\
\text { concrete }\end{array}$} & \multicolumn{4}{|c|}{$\mathrm{Kg} / \mathrm{m}^{3}$} \\
\hline & & & concrete & Water & vermiculite & fiber \\
\hline \multirow{4}{*}{ Basalt } & 0 & \multirow{4}{*}{1,1} & \multirow{4}{*}{581,4} & \multirow{4}{*}{639,5} & \multirow{4}{*}{318,6} & 0 \\
\hline & 1 & & & & & 15,39 \\
\hline & 2 & & & & & 30,79 \\
\hline & 4 & & & & & 61,58 \\
\hline \multirow{4}{*}{ Polypropylene } & 0 & \multirow{4}{*}{1} & \multirow{4}{*}{606,7} & \multirow{4}{*}{606,7} & \multirow{4}{*}{332,5} & 0 \\
\hline & 0,5 & & & & & 7,73 \\
\hline & 1 & & & & & 15,46 \\
\hline & 2 & & & & & 30,92 \\
\hline
\end{tabular}

The finished mixture shapes and compacts on the vibrating platform. The flexural strength determines on samples measuring 40x40x160mm and the compression onesis on the half beams. The samples keep in conditions of $100 \%$ humidity at $\mathrm{t}=20 \pm 1^{\circ} \mathrm{C}$ and test on the "UTS - 250" installations after 28 days. The results of the research present in Figures 2, 3 and in Tables 2, 3.

Table 2. Effect of fiber on the strength of vermiculite concrete

\begin{tabular}{|c|c|c|c|c|c|c|c|c|}
\hline \multirow{2}{*}{$\begin{array}{c}\text { Type } \\
\text { of } \\
\text { fiber }\end{array}$} & \multirow[b]{2}{*}{$\begin{array}{c}\text { Fibercontent, } \\
\%\end{array}$} & \multirow[b]{2}{*}{$\begin{array}{c}\text { Water/ } \\
\text { concrete }\end{array}$} & \multicolumn{3}{|c|}{ flexural } & \multicolumn{3}{|c|}{ compressive } \\
\hline & & & $\mathrm{MPa}$ & $\%$ & $\begin{array}{c}\mathrm{V}_{\mathrm{m}}^{*}, \\
\%\end{array}$ & $\mathrm{MPa}$ & $\%$ & $\mathrm{~V}_{\mathrm{m}}, \%$ \\
\hline \multirow{4}{*}{$\begin{array}{l}\text { VS23- } \\
6-61\end{array}$} & 0 & \multirow{4}{*}{1,1} & 3,12 & 100 & 9,2 & 5,71 & 100 & 1,2 \\
\hline & 1 & & 3,60 & 115 & 18,6 & 8,10 & 142 & 2,2 \\
\hline & 2 & & 4,30 & 138 & 4,4 & 9,61 & 168 & 6,2 \\
\hline & 4 & & 4,40 & 141 & 10,0 & 10,43 & 183 & 1,2 \\
\hline \multirow{4}{*}{$\begin{array}{l}\text { VSM- } \\
6\end{array}$} & 0 & \multirow{4}{*}{1} & 4,03 & 100 & 5,3 & 7,80 & 100 & 11,7 \\
\hline & 0,5 & & 4,13 & 102 & 11,0 & 8,43 & 108 & 9,9 \\
\hline & 1 & & 4,07 & 101 & 8,5 & 8,55 & 110 & 2,7 \\
\hline & 2 & & 5,63 & 140 & 14,5 & 8,15 & 105 & 3,7 \\
\hline
\end{tabular}

$\mathrm{Vm} *$-coefficient of variation

Table 3. Average density of vermiculite concrete samples

\begin{tabular}{|c|c|c|c|c|}
\hline Type of fiber & $\begin{array}{c}\text { Water/ } \\
\text { concrete }\end{array}$ & $\begin{array}{c}\text { Density at natural } \\
\text { moisture, } \mathrm{kg} / \mathrm{m}^{3}\end{array}$ & $\begin{array}{c}\text { Dry density, } \\
\mathrm{kg} / \mathrm{m}^{3}\end{array}$ & Moisture, \% \\
\hline VS23-6-61 & 1,1 & 1511 & 1031 & 47 \\
\hline BSM-6 & 1 & 1497 & 1072 & 40 \\
\hline
\end{tabular}

As can be seen from table 2 and graphs presenting in figure 2, the greatest increase in the flexuralstrength of vermiculite concrete at $40 \%$ observes with 2 and $2 \div 4 \%$ polypropylene and basalt fiber, respectively. 


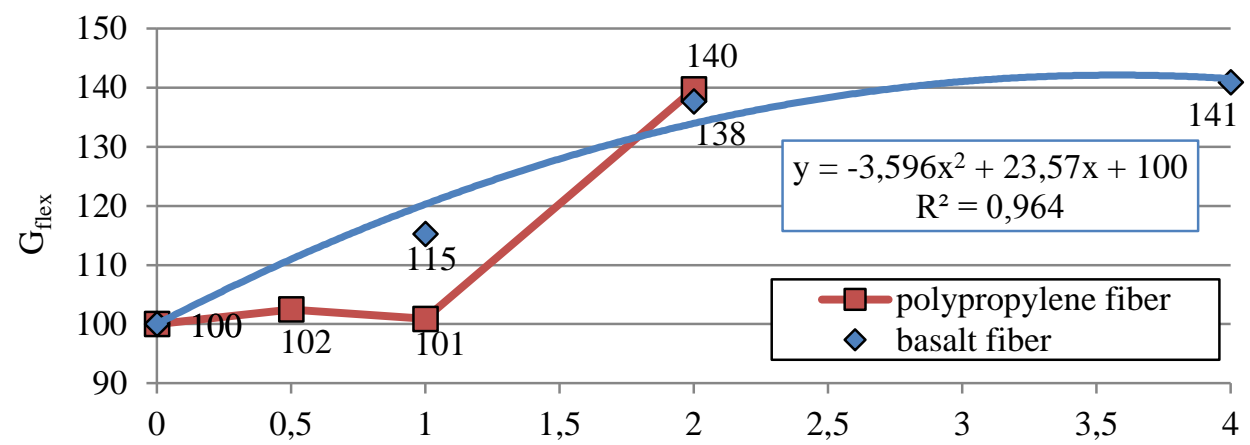

Fibrecontent, \%

Fig. 2. Variation of the flexural strength of the heat-protection vermiculite concreteaccording to the fiber content

With an increase in basalt fiber content (fig. 3) from 1 to $4 \%$, the compressive strength increases from 42 to $83 \%$, respectively. At the same time, there has been no significant increase in compressive strength during fiber reinforcement with polypropylene fiber.

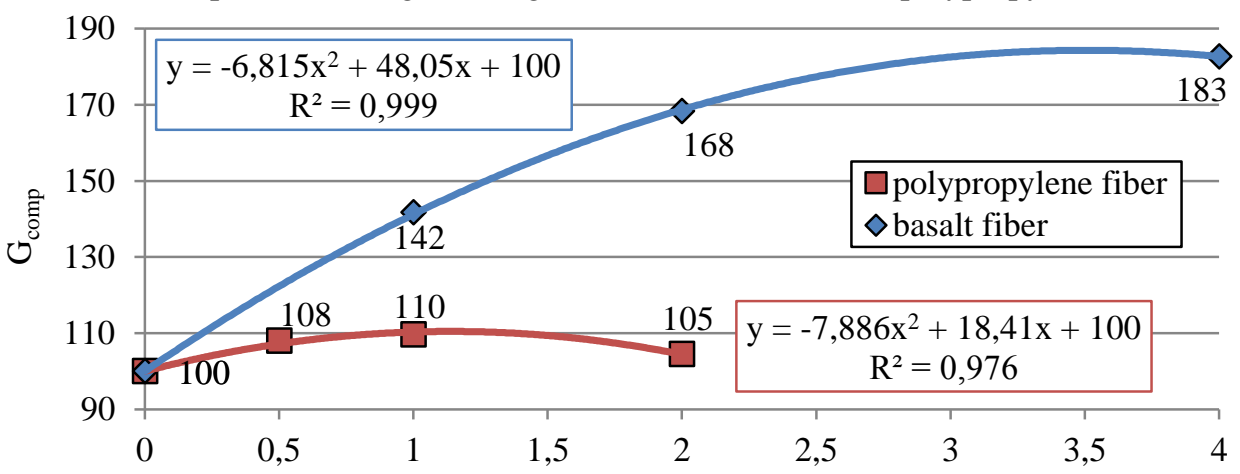

Fibrecontent, \%

Fig. 3. Relative variation of the compression strength of the heat-protection vermiculite concrete according to the fiber content

In our opinion, one of the main goals of composites based on cement/concrete matrix is to increase the viscosity of the material's destruction. For example, the passport characteristics of concrete are flexural and compressive strength- under static loads, but the torque-concrete fastenings and coatings erected in mines and mines are subject to more dynamic (instantaneous) effects energy rate. The performance of these designs in such impacts can be estimated by the energy intensity of destruction $[9,10]$.

The resistance of vermiculite concrete to dynamic loads determines on pendulum and vertical pile driver. A sample of the investigated building material with dimensions of $25 \times 25 \times 100 \mathrm{~mm}$, lying on two supports, subjects to the impact of a pendulum, and the impact line is in the middle between the supportswhen tested on a BKM-5-2 pendulum pile driver.

Specific energy intensity of destruction of samples $(\mathrm{K})$ defines as ratio of working $(\mathrm{W})$, spent on its destruction, to square $\left(\mathrm{S}_{0}\right)$ of the sample in impact plane [9]:

$$
\mathrm{K}=\mathrm{W} / \mathrm{S}_{0}, \mathrm{~J} . / \mathrm{m}^{2}
$$

where $W$ - energy consumption for destruction of the sample along the pendulum, J.; $S_{0}$ - area of the formed surface at the fracture site of the sample, $\mathrm{m}^{2}$. 
The specific energy intensity of the destruction of fine-grained concrete determines on the vertical pile driver by K. I. Syskov according to the previously developed methodology of Institute of Mining of the North SB RAS [10]. Samples of regular concrete of a $24 \times 24$ $\times 14 \mathrm{~mm}$ are crushed. To assess the energy intensity of destruction of concrete of a given composition, five weighed portions of samples weighing about $50 \mathrm{~g}$ each are made. Each weighed portion of the test material is placed in a loading cup of a pile driver andcrushed by dropping a weight of $2.4 \mathrm{~kg}$ from a constant height of $0.6 \mathrm{~m}$. The number of cargo drops determines in accordance with GOST 21153.1-75. The results of the tests presents in table 4.

Table 4. Effect of fiber on the resistance of vermiculite concrete to dynamic loads

\begin{tabular}{|c|c|c|c|c|c|c|c|}
\hline \multirow{2}{*}{\multicolumn{2}{|c|}{ Fiber }} & \multicolumn{6}{|c|}{ Energy intensity of destruction } \\
\hline & & \multicolumn{3}{|c|}{ Pendulum pile driver } & \multicolumn{3}{|c|}{ Vertical pile driver } \\
\hline mark & content, $\%$ & $\mathrm{~J} / \mathrm{m}^{2}$ & $\%$ & $\mathrm{Vm}, \%$ & 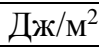 & $\%$ & $\mathrm{Vm}, \%$ \\
\hline \multirow{4}{*}{$\begin{array}{c}\text { VS23- } \\
6-61\end{array}$} & 0 & 512 & 100 & 8,8 & 3241 & 100 & 5,9 \\
\hline & 1 & 752 & 147 & 11,0 & 7339 & 226 & 16,5 \\
\hline & 2 & 1089 & 213 & 9,7 & 8444 & 261 & 5,9 \\
\hline & 4 & 1303 & 254 & 21,6 & 8895 & 274 & 15,9 \\
\hline \multirow{3}{*}{ VSM-6 } & 0,5 & 1256 & 245 & 8,1 & $\mathrm{x}^{* *}$ & $\mathrm{x}^{* *}$ & $\mathrm{x}^{* *}$ \\
\hline & 1 & 2041 & 398 & 8,3 & $\mathrm{x}^{* *}$ & $\mathrm{x}^{* *}$ & $\mathrm{x}^{* *}$ \\
\hline & 2 & 2148 & 419 & 8,9 & $\mathrm{x}^{* *}$ & $\mathrm{x}^{* *}$ & $\mathrm{x}^{* *}$ \\
\hline
\end{tabular}

$* *$ the calculation of the energy intensity of fracture on these samples is not carried out, since after crushing on a vertical pile driver, the samples of fiber-reinforced polypropylene fiber series, in contrast to the control (unreinforced) and reinforced with basalt fiber, did not collapse, but were covered with cracks and deformed (Fig. 4). In our opinion, this is due to the fact that polypropylene fibers, in contrast to basalt ones, have a higher elongation coefficient of up to $25 \%$.

It should be noted that despite the impossibility of a correct assessment of the specific energy consumption of destruction of vermiculite concrete reinforced with polypropylene fiber, it prevents the destruction of the samples under study, which indicates an increase in their physical and mechanical characteristics. As can be seen from the graphs presented in Fig. 5 and the tables. 4 polypropylene fiber substantially increases the resistance of vermiculite concrete to dynamic flexural loads by $2,5 \div 4,2$ times. At the same time, with the content of basalt fiber in an amount of 1 to $4 \%$, the energy intensity of vermiculite concrete destruction increases by $1.5 \div 2.5$ times.

In case of volumetric fracture of the samples on a vertical pile driver, the specific energy intensity of destructionof samples reinforced with basalt fiber increases by $2,3 \div 2,7$ times.

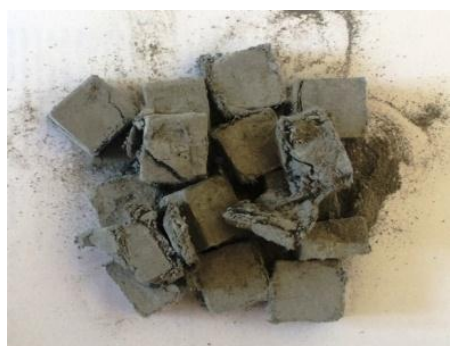

a) polypropylene fiber $1 \%$

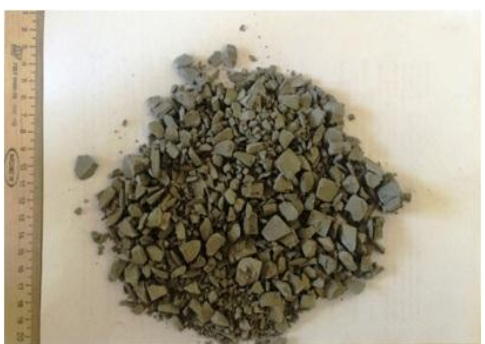

b) crushed material

Fig. 4. The state of the test samples after crushing on a vertical pile driver 


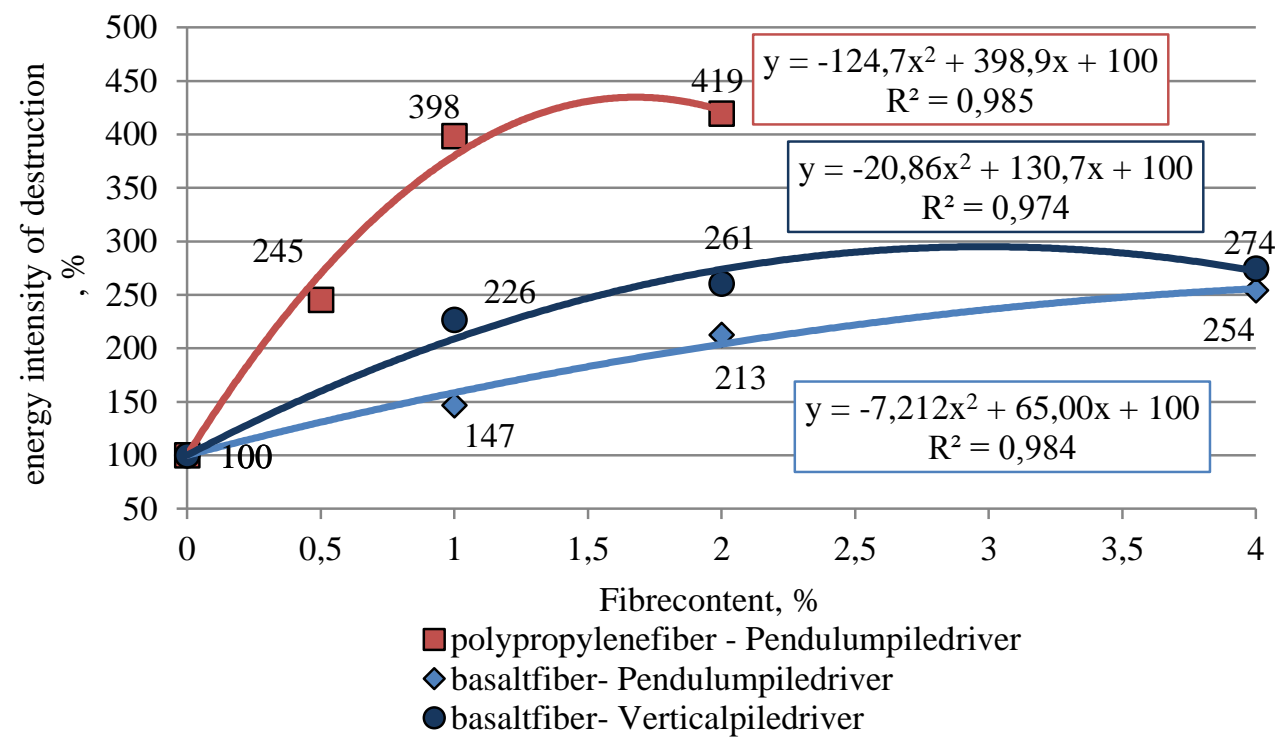

Fig. 5. Relative changes in the energy intensity of vermiculite concrete destruction according to fiber content (pendulum pile driver)

\section{Conclusion}

The resulting patterns show that the dispersed reinforcement of light thermal vermiculite concrete by basalt or polypropylene fiber can increase its resistance to both static and dynamic loads. As a result, broaden the scope of its use, extend useful life, contribute to the safety of the permafrost mines by building heat-shielding monolith and shortcrete supports fastenings.

\section{References}

1. A. S. Kurilko. Experimental studies on the impact of freezing-thawing cycles on the physical and mechanical properties of rocks. Yakutsk: Published by Yakutsk Scientific Center (2004)

2. I. V. Avksent'ev, V. N. Skuba Insulation of mine workings in permafrost zone, (Novosibirsk: Nauka, 1983)

3. A. F. Galkin, V. V. Kiselev, A. S. Kurilko. Sprayed concrete heat-shielding support Yakutsk: Published House of Yakutsk Scientific Center, SB, RAS (1992)

4. P. N. Vasilyev, A. S. Kurilko, Y. A. Khokholov, V. A. Sherstov. The thermal regime of the Yakutia coal mines and methods of it is regulations. Yakutsk: Published House of Yakutsk Scientific Center, SB, RAS (2009)

5. D.E. Solovev, Yu. A. Khokholov, V. E. Zakharov Alteration of the contour of unbound mining under freezing-thawing cycles, All Russian scientific-practical conference dedicated to the memory of Corresponding Member the Russian Academy of Sciences M. D. Nopopashin. Yakutsk, published by Permafrost Institute, Siberian Branch, RAS. 270$273(2011)$

6. F. Saber, N. Mahdi. Mechanical properties and durability of high-strength concrete containing macro-polymeric and polypropylene fibers with nano-silica and silica fume. ConstructionandBuildingMaterials, 132 (2017) 
7. F. M. Rabinovich.Composites based on dispersed concrete. Theory and design, technology and design issues.Moscow: ACB (2004)

8. Cory H, Hatem M. Seliem, Adel El-Safty, Sami H. Rizkalla. Use of basalt fibers for concrete structures.Construction and Building Materials, 96 (2015)

9. K. N. Alekseev, A. S. Kurilko, E. V. Zakharov. GIAB, 12, 56-63 (2017)

10. E. V. Zakharov. Nauka i obrazovaniye, 3, 82-85 (2017) 